\title{
Population and Society: An Introduction to Demography
}

\author{
by Dudley L. Poston, Jr., and Leon F. Bouvier \\ New York: Cambridge University Press 2010 \\ ISBN 978-0-52187-287-4 \\ Hardcover, \$72.00, xv+456 pp.
}

\author{
Reviewed by Amir Erfani \\ Nipissing University (North Bay, ON) \\ amire@nipissingu.ca
}

This book with fourteen chapters is a new demography textbook, written by two renowned demographers. The chapters cover all standard concepts, techniques, theoretical perspectives, and debates on population at individual and aggregate levels that are taught in standard demography courses. The authors' international research expertise and their sociological orientation in linking population dynamics to changes in societal institutions make the book distinct from other demography textbooks. The book is a solid introduction to social demography that links demographic issues and phenomena to their relevant sociological and economic explanations and implications, while providing adequate methodologies in demography. The volume is recent and includes timely and new concepts and issues in demography, such as male fertility and replacement migration as a strategy to deal with low fertility.

Its clear and easy language makes the volume accessible to a wide range of audiences. The comparison of demographic characteristics and processes between the United States and China brings a special flavour to the text. The use of lively examples on migration, mortality, fertility control, and population policy taken from these two countries helps the readers to understand demographic issues and to consider themselves as "population actors." For example, the effect of demographic processes on age structure, and the socioeconomic consequences of this effect, have been competently illustrated by an example of baby boomers in the United States (p. 8). Compared with similar textbooks, this volume describes basic demographic concepts and measures efficiently, with little confusion. For example, the concept of reproduction has been properly distinguished from fertility when defining the gross reproduction rate ( $\mathrm{p}$. 49). Students taking demography courses often struggle to learn demographic measures and methods. Poston and Bouvier, however, successfully address this issue by describing the logic and rationale behind a measure, while showing how to correctly interpret the outcome of the method.

The book is divided into fourteen chapters. Chapter 1 defines demography and briefly introduces the topics covered by the other chapters. In chapter 2 , the authors discuss different sources of demographic data, including an introduction to World Fertility Surveys and Demographic Health Surveys as the most reliable sources of demographic data in developing countries. Similar to any standard introductory textbook on demography, the authors cover all the hallmark topics, namely, world population change over time, age-sex composition, population distribution, fertility, mortality, internal and international migration, population policy, and the future of the world population, in nine more chapters. The authors devote two chapters to the United States. One chapter describes population change in the United States, and the other one contains discussions on the changing race and ethnic distribution of the United States and its implications and consequences. There are also a glossary defining the key concepts presented in the book, a list of references, and author and subject indexes.

Contrary to other textbooks, Poston and Bouvier devote one chapter to "Contraception and Birth Control." As they state, "a discussion of fertility is incomplete without a consideration and review of contraception and birth control." This chapter can be particularly of great interest to international readers in developing countries who are engaged with issues related to family planning and its role in bringing down high fertility rates. As a proximate determinant of fertility, contraception is still of great importance to demographers and policymakers around the world. 
The chapter adequately introduces various traditional and modern contraceptive methods. The failure rate, advantages, and disadvantages of each contraceptive method are thoroughly discussed.

As a context of childbearing and rearing that affects the fertility rate in a society, nuptiality has typically been covered in one chapter in standard demography textbooks. It is, however, unfortunate that this book has no section or chapter on such an important, timely subject. The recent changes in union formation and nuptiality, observed in developed countries and parts of Asia, have affected couples' childbearing decision making. The increasing rates of divorce, the postponement of family formation and childbearing, the emergence of a multitude of living arrangements other than marriage, and important ideational shifts from familism to individualism are issues that have been documented to be associated with sub-replacement fertility levels in these countries. The reviewer would have liked to see a chapter on nuptiality and transformation in conjugal life and its link with below-replacement or very low fertility.

At different places in the book, the reader is hard-pressed to read and understand the information illustrated in a number of graphs and tables. For example, the names of 205 countries in Figure 3.4, which illustrates total fertility rates, are too small to read, and the figure legends are poorly developed.

Regardless of the limitations, Population and Society: An Introduction to Demography is a welcome new textbook which is an essential, comprehensive source for teaching demography to a wide rage of audiences in the social sciences. Poston and Bouvier's book is an ideal text for undergraduate and graduate students taking their first courses in demography and population studies. Also, it warrants reading by all who are interested in population change and cultural adaptation in the United States. 